PAULA JT; RESENDE JTV; FARIA MV; FIGUEIREDO AST; SCHWARZ K; NEUMANN ER. 2015. Características físico-químicas e compostos bioativos em frutos de tomateiro colhidos em diferentes estádios de maturação. Horticultura Brasileira 33: 434-440. http://dx.doi.org/10.1590/S0102053620150000400005

\title{
Características físico-químicas e compostos bioativos em frutos de tomateiro colhidos em diferentes estádios de maturação
}

\author{
Juliana T Paula; Juliano TV Resende; Marcos V Faria; Alex ST Figueiredo; Kélin Schwarz; Edina R \\ Neumann \\ Universidade Estadual do Centro-Oeste (UNICENTRO), Guarapuava-PR, Brasil; jtaufferp@gmail.com; jvresende@uol.com.br; \\ mfaria@unicentro.br; alex_figueiredo1987@yahoo.com.br; kelinschwarz@hotmail.com; edyna18@hotmail.com
}

\section{RESUMO}

Frutos de tomateiro são colhidos em estádios pouco avançados de maturação em função da distância entre mercados consumidores assim como para se obter maior tempo de prateleira. Sabe-se que o estádio de maturação no momento da colheita interfere diretamente na qualidade do fruto. O objetivo desse estudo foi avaliar as características físico-químicas e os compostos bioativos de frutos de tomateiro (cultivares AP-529 e Tinto) em função da colheita em cinco estádios de maturação (verde-maduro, verde-rosado, rosa-esverdeado, róseo e vermelho-claro). As características físico-químicas avaliadas foram firmeza, teor de sólidos solúveis (TSS), acidez titulável (AT), relação TSS/AT e açúcares redutores. Os compostos bioativos avaliados foram: ácido ascórbico, compostos fenólicos e licopeno. O híbrido AP-529 teve destaque nos teores de compostos fenólicos, licopeno e acidez titulável; o híbrido Tinto se destacou no teor de açúcares redutores, ácido ascórbico e relação TSS/AT. A colheita dos frutos em estádios menos avançados de maturação favoreceu as características firmeza, sólidos solúveis, acidez titulável, açúcar redutor e licopeno, enquanto que a colheita em estádios mais avançados de maturação favoreceu a relação TSS/AT, compostos fenólicos e ácido ascórbico.

Palavras-chave: Solanum lycopersicum, qualidade, colheita, antioxidantes.

\begin{abstract}
Physicochemical characteristics and bioactive compounds in tomato fruits harvested at different ripening stages

Tomato fruits are harvested in stages less advanced of maturation depending on the distance between consumer markets as well as to obtain the greatest time of shelf life. Assuming that the stage of maturity at the time of harvest directly influences fruit quality, the objective of this study was to evaluate the physical and chemical characteristics and the bioactive compounds of tomato fruits (cultivars AP-529 and Tinto) depending on harvest in five stages of maturation (mature-green, green-pink, pink-green, pink and light-red). The evaluated physico-chemical characteristics were firmness, soluble solids content (TSS), titratable acidity (TA), relation TSS/TA and reducing sugars and the bioactive compounds ascorbic acid, phenolic compounds and lycopene. The hybrid AP-529 had highlighted the levels of phenolic compounds, lycopene and titratable acidity; the hybrid Tinto stood out on the content of reducing sugars, ascorbic acid and TSS/TA. The harvest of fruits in less advanced stadiums of maturation favored the characteristics of firmness, soluble solids, titratable acidity, reducing sugars and lycopene, while the harvest in more advanced stages of maturation favored the TSS/TA, phenolic compounds and ascorbic acid contents.
\end{abstract}

Keywords: Solanum lycopersicum, quality, harvest, antioxidants.

(Recebido para publicação em 7 de novembro de 2014; aceito em 16 de abril de 2015) (Received on November 7, 2014; accepted on April 16, 2015)

$\mathrm{O}$ tomateiro é cultivado em quase todos os estados do país, dividindo sua produção em tomate para mesa e para processamento, porém, mesmo com o crescimento da área cultivada de tomate industrial, a maior parte da produção é destinada ao consumo in natura (Mattedi et al., 2007). Em certas épocas do ano alguns produtores têm comercializado tomates industriais, oriundos de cultivares de crescimento determinado, para consumo in natura; são as chama- das cultivares com dupla-aptidão.

A qualidade de um fruto na pós-colheita se relaciona diretamente com o seu ponto de colheita e maturação. Muitos trabalhos têm relatado que características físico-químicas, como teor de açúcar, acidez e compostos bioativos em tomate são fortemente influenciados pelas diversas práticas culturais e aspectos agronômicos, particularmente o genótipo e o estádio de maturação do fruto (Binoy et al., 2004; Garcia \&
Barrett, 2006). Os principais compostos bioativos em tomate são os flavonóides (rutina, kaempferol e naringenina) e ácidos fenólicos (ácido caféico, ácido p-cumárico e ácido ferúlico) (Long et al., 2006).

$\mathrm{O}$ amadurecimento dos frutos de tomate envolve várias alterações fisiológicas, bioquímicas e moleculares, incluindo degradação da clorofila e síntese e armazenamento de carotenoides, particularmente licopeno (Lopez-Juez, 
2007). Outros antioxidantes importantes, como os compostos fenólicos, também apresentam modificações nos seus teores durante o amadurecimento (Raffo et al., 2002). Consequentemente, para uma comparação mais precisa dessas características entre as cultivares, é necessário uma amostragem bastante cuidadosa, visando comparar apenas os frutos colhidos no mesmo estádio de maturação fisiológica.

O ponto de colheita do tomate depende, de maneira geral, da distância entre o local de produção até o atacado ou a indústria de processamento e também da preferência do consumidor e do mercado. Todavia, tomate colhido maduro tem sabor e aroma superiores aos do tomate colhido em estádios de amadurecimento anteriores (Alvarenga, 2004). Os frutos a serem colhidos devem apresentar um grau de maturação que proporcione uma maior flexibilidade de comercialização e também que agrade o consumidor. Os frutos apresentam, de maneira geral, suas melhores características de qualidade quando completam sua maturação (estádio vermelho) ligados na planta mãe. Porém, nem sempre podem ser colhidos nesse ponto, devido à maior perecibilidade e sensibilidade ao manuseio e transporte.

A análise físico-química e de diferentes compostos bioativos em frutos de tomateiro é de grande relevância tanto para a saúde humana como para fins comerciais. Diante disso, esse trabalho teve como objetivo avaliar as características físico-químicas e os compostos bioativos de frutos de tomateiro de duas cultivares de crescimento determinado, em função da colheita em cinco estádios de maturação.

\section{MATERIAL E MÉTODOS}

O experimento foi realizado na Universidade Estadual do Centro-Oeste (UNICENTRO), no Setor de Olericultura do Campus Cedeteg, em Guarapuava-PR (2523'36”S, 51²7'19'O, altitude $1.120 \mathrm{~m})$. Segundo a classificação de Köppen, o clima da região é $\mathrm{Cfb}$ (subtropical úmido mesotérmico). A temperatura média máxima anual é de $23,5^{\circ} \mathrm{C}$ e a média mínima de $12,7^{\circ} \mathrm{C}$. A precipitação média anual é de $2.022 \mathrm{~mm}$, e a temperatura média anual de $16,5^{\circ} \mathrm{C}$.

Foram utilizados no experimento dois híbridos comerciais tipo saladete de crescimento determinado: AP-529 e Tinto. A semeadura dos híbridos foi realizada em bandejas de poliestireno com 200 células preenchidas com substrato Plantmax ${ }^{\circledR}$ e mantidas em ambiente protegido por 32 dias. O transplantio ocorreu quando as mudas apresentavam em torno de $20 \mathrm{~cm}$ e de cinco a seis folhas verdadeiras. Com relação ao delineamento experimental, os tratamentos a campo foram em blocos casualizados com quatro repetições. Cada parcela experimental foi constituída por 12 plantas distribuídas em fileira dupla com 6 plantas cada. $\mathrm{O}$ espaçamento utilizado foi de $1,30 \mathrm{~m}$ entre fileiras e $0,40 \mathrm{~m}$ entre plantas.

A análise do solo $(0-20 \mathrm{~cm})$ revelou: $\mathrm{pH}=5,8 ; \mathrm{Ca}, \mathrm{Mg}, \mathrm{K}, \mathrm{Al}, \mathrm{H}+\mathrm{Al}$, CTCt e $\mathrm{SB}\left(\mathrm{cmol} / \mathrm{dm}^{3}\right)=5,8,6,4,2,6,0,3,0$, 2,9,12,14 e 9,25; P (mg/dm $\left.{ }^{3}\right)=0,15 ; \mathrm{MO}$ $\left(\mathrm{g} / \mathrm{dm}^{3}\right)=28,3 \mathrm{e}, \mathrm{V}(\%)=76$. A adubação ocorreu conforme resultado da análise de solo e, seguindo o recomendado para a cultura (Silva \& Giordano, 2000) sendo realizada uma adubação no momento do transplante, e duas adubações de cobertura [uma no início da floração (30 dias após o transplantio) e outra durante a frutificação (50 dias após o transplantio)].

As plantas daninhas foram controladas por capinas manuais em todo o ciclo da cultura. O controle de pragas e doenças foi realizado semanalmente por meio de aplicações de inseticidas e fungicidas nas doses recomendadas para a cultura. Semanalmente ocorria também aplicação foliar de cálcio para evitar o aparecimento de podridão apical.

Os frutos foram colhidos em cinco estádios de maturação, identificados pelo desenvolvimento de cor (Alvarenga, 2004): Estádio 1, verde-maduro (o fruto encontra-se na maturidade fisiológica e apresenta $100 \%$ da sua superfície na coloração verde, podendo essa variar de tonalidade); Estádio 2, verde-rosado (pequena mudança de cor, do verde para avermelhado na extremidade distal do fruto, ficando de 0 a $10 \%$ da superfície avermelhada ou amarelada, dependendo da cultivar); Estádio 3, rosa-esverdeado (a coloração do fruto encontra-se de 10 a 30\% avermelhada, rosa ou amarela, ou a combinação entre essas cores, também dependendo da cultivar); Estádio 4, róseo (30 a $60 \%$ da superfície do fruto apresenta-se avermelhada ou rósea, dependendo da cultivar); Estádio 5, vermelho-claro (60 a 90\% da superfície do fruto com coloração róseo-vermelha ou vermelha, de acordo com a cultivar).

Para a análise colheu-se frutos no estádio 6 de maturação [vermelhos (mais de 90\% da superfície do fruto com coloração vermelho-intensa)]. A seleção constou somente de frutos com padrão comercial, sendo descartados aqueles considerados refugo (frutos com podridão, danificados por pragas, com rachaduras ou muito pequenos ( $>30 \mathrm{~g})$.

Os frutos colhidos e selecionados em campo foram encaminhados ao Laboratório de Fisiologia Vegetal da UNICENTRO onde foram lavados em água corrente. Todos os tratamentos foram deixados em temperatura (média de $22^{\circ} \mathrm{C}$ ) e umidade relativa ambiente (55\%) durante a total realização do experimento.

O delineamento experimental utilizado em laboratório foi inteiramente casualizado em esquema fatorial $2 \times 5$ (híbridos x estádios de maturação), constituído de quatro repetições de seis frutos por repetição.

As primeiras análises realizadas constaram da firmeza (F), teor de sólidos solúveis (TSS), acidez titulável (AT) e ácido ascórbico (AA). Após determinação da firmeza, os frutos foram triturados em um triturador doméstico e sua polpa congelada em freezer $\left(-20^{\circ} \mathrm{C}\right)$ enquanto se procedia às primeiras análises. Posteriormente as polpas foram submetidas às análises de açúcares redutores (AR), compostos fenólicos (CF) e licopeno (LI).

A firmeza, medida em Newton foi determinada com o auxílio de um penetrômetro digital (Soil Control PDF200) com ponteira de $8 \mathrm{~mm}$, mediante compressão exercida sobre a polpa. Foram feitas duas leituras em cada fruto do tratamento na região equatorial. $\mathrm{O}$ teor de sólidos solúveis foi obtido pela leitura direta em refratômetro digital portátil (Modelo PAL-1), utilizando polpa homogeneizada e filtrada em al- 
godão, obtendo-se os valores em graus Brix. O ácido ascórbico foi determinado pelo método titulométrico com solução DCFI (2,6-diclorofenol-indofenol) padronizada, até obter o ponto de viragem; esse método é padrão da AOAC modificado por Benassi \& Antunes (1988). Os resultados foram expressos em $\mathrm{mg}$ ácido ascórbico/100 g de polpa. A acidez titulável foi obtida empregando solução padrão de $\mathrm{NaOH}$ 0,1 N. A titulação foi cessada quando o $\mathrm{pH}$ da solução atingiu 8,2 , sendo esse o ponto de viragem. Essa técnica é padronizada pelo Instituto Adolfo Lutz (2005). Os resultados foram expressos em gramas de ácido cítrico por $100 \mathrm{~g}$ de polpa. Depois de obtidos os valores de TSS e AT foi feita a relação entre ambos dividindo-se o valor TSS pelos valores de AT.

Os açúcares redutores (\%) foram determinados pelo método titulométrico de Lane-Eynon, descrito pelo Instituto Adolfo Lutz (2005). A titulação foi realizada com a amostra em uma solução em ebulição de reagentes Fehlings até alcançar o ponto de viragem, quando a cor azul da mistura dos Fehlings passa a incolor com resíduo em $\mathrm{Cu}_{2} \mathrm{O}$ no fundo de coloração vermelho-tijolo. A determinação dos compostos fenólicos foi realizada de acordo com Singleton \& Rossi (1965) baseando-se no método espectrofotométrico de Follin-Ciocauteau. As amostras foram deixadas por 2 horas em ambiente escuro para posterior leitura. A leitura foi feita em espectrofotômetro SP-2000UV Spectrum a $765 \mathrm{~nm}$. Os resultados foram expressos em $\mathrm{mg}$ de equivalente ácido gálico (GAE)/100 $\mathrm{g}$ de polpa. O teor de licopeno foi determinado pela metodologia descrita por Rodriguez-Amaya (2001), utilizando análise espectrofotométrica, com leitura a $470 \mathrm{~nm}$. Os resultados foram expressos em $\mu \mathrm{g}$ de licopeno por $g$ de polpa.

Todos os dados obtidos foram submetidos à análise de variância (teste F), utilizando o software SISVAR 5.3. As características que apresentaram médias com diferença estatística significativa entre os híbridos ou estádios de maturação foram comparadas pelo teste de Tukey $(\mathrm{p} \leq 0,05)$.

\section{RESULTADOS E DISCUSSÃO}

Os resultados da análise de variância revelaram diferenças significativas $(\mathrm{p}<0,05)$ para todas as características avaliadas dentro dos híbridos (exceto

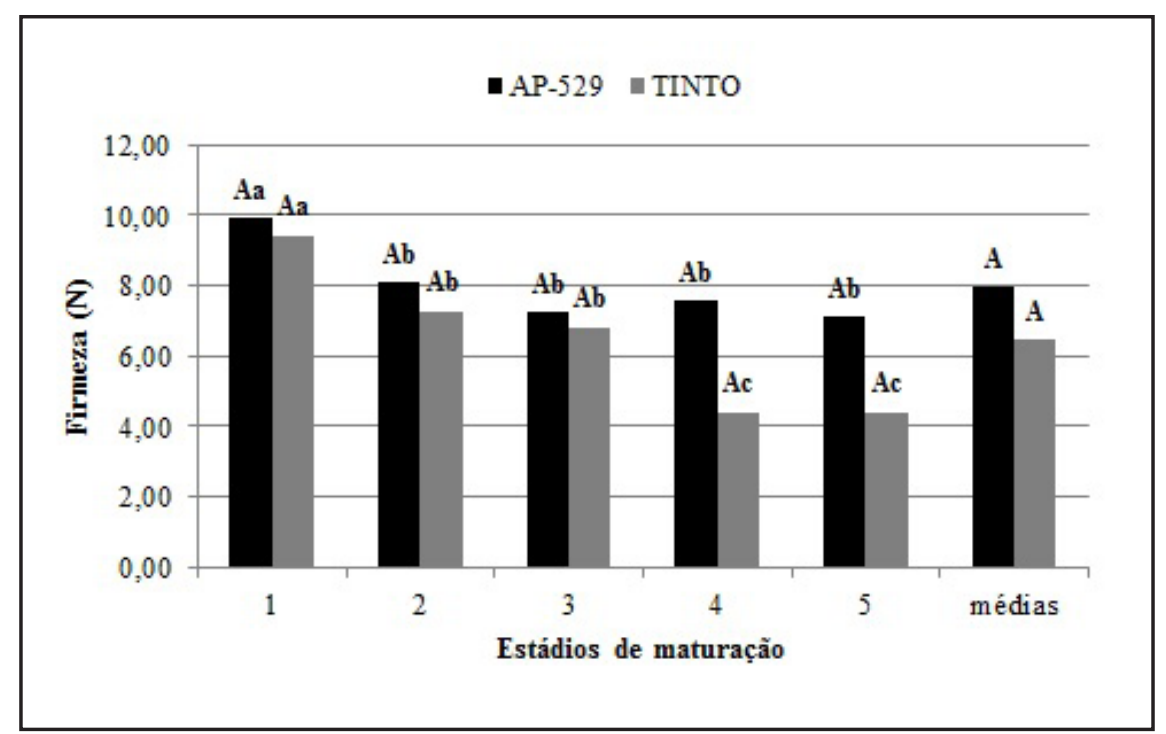

Figura 1. Firmeza de fruto $(\mathrm{N})$ em híbridos de tomateiro colhidos em cinco estádios de maturação e avaliados no sexto estádio de maturação \{fruit firmness $(\mathrm{N})$ in tomato hybrids harvested at five maturity stages and evaluated in the sixth stage of maturation\}. Letras maiúsculas comparam híbridos e letras minúsculas comparam estádios de maturação. Médias seguidas pela mesma letra (maiúscula ou minúscula) não diferem estatisticamente entre si pelo teste de Tukey a 5\% (uppercase and lowercase letters compare hybrids and maturation stages, respectively. Means followed by the same uppercase or lowercase letter did not differ significantly by the Tukey test at 5\%). Guarapuava, UNICENTRO, 2014. para característica firmeza), estádios e interação híbrido vs. estádios. Dessa forma, os resultados serão apresentados e discutidos em função das médias dos estádios e dos genótipos.

O valor médio de firmeza foi de 8,0 $\mathrm{N}$ para o híbrido AP-529 e de 6,47 para o híbrido Tinto (Figura 1); entretanto, não houve diferença estatística entre eles. Observa-se para estádios de maturação, que frutos colhidos no estádio 1 apresentam maior firmeza $(9,92 \mathrm{~N}$ para o AP-529 e 9,43 N para o Tinto), que nos demais estádios (Figura 1). Em trabalho realizado por Ferreira et al. (2012) com o híbrido 'SM-16', verificou-se que tomates pertencentes aos estádios menos avançados de maturação apresentaram firmeza de polpa maior do que frutos colhidos mais maduros, concordando com os resultados encontrados. Essa maior firmeza em frutos colhidos verdes e amadurecidos fora da planta mãe é atribuída à sua maior resistência no momento da colheita, tendo em vista que frutos colhidos maduros já se apresentam menos firmes e dessa forma menos resistentes a impactos.

Segundo Vries et al. (1995), frutos colhidos em estádios menos avançados de maturação e amadurecidos após a colheita apresentam menor produção de etileno devido a uma difusão facilitada deste hormônio gasoso, pela cicatriz peduncular do fruto, diminuindo sua concentração interna. O etileno tem um importante papel na regulação da expressão da enzima poligalacturonase, a qual, juntamente com a pectinametilesterase são responsáveis pela solubilização das substâncias pécticas da parede celular. Essa solubilização amacia o fruto, pois há uma diminuição das forças coesivas que mantêm as células unidas, e consequentemente a firmeza diminui (Sitrit \& Bennett, 1998).

Com relação ao TSS, na média, não houve diferença entre os híbridos, onde ambos apresentam 4,2 ${ }^{\circ}$ Brix (Figura 2). Entre os estádios de maturação, observa-se que para ambos híbridos, frutos colhidos em estádios menos avançados de maturação, apresentam maiores TSS. Para o híbrido AP-529, no estádio 1 obteve-se o maior TSS $\left(4,33^{\circ}\right.$ Brix) e no estádio 5 o menor valor $\left(4,13^{\circ}\right.$ Brix $)$. $\mathrm{O}$ híbrido Tinto apresentou os maiores 


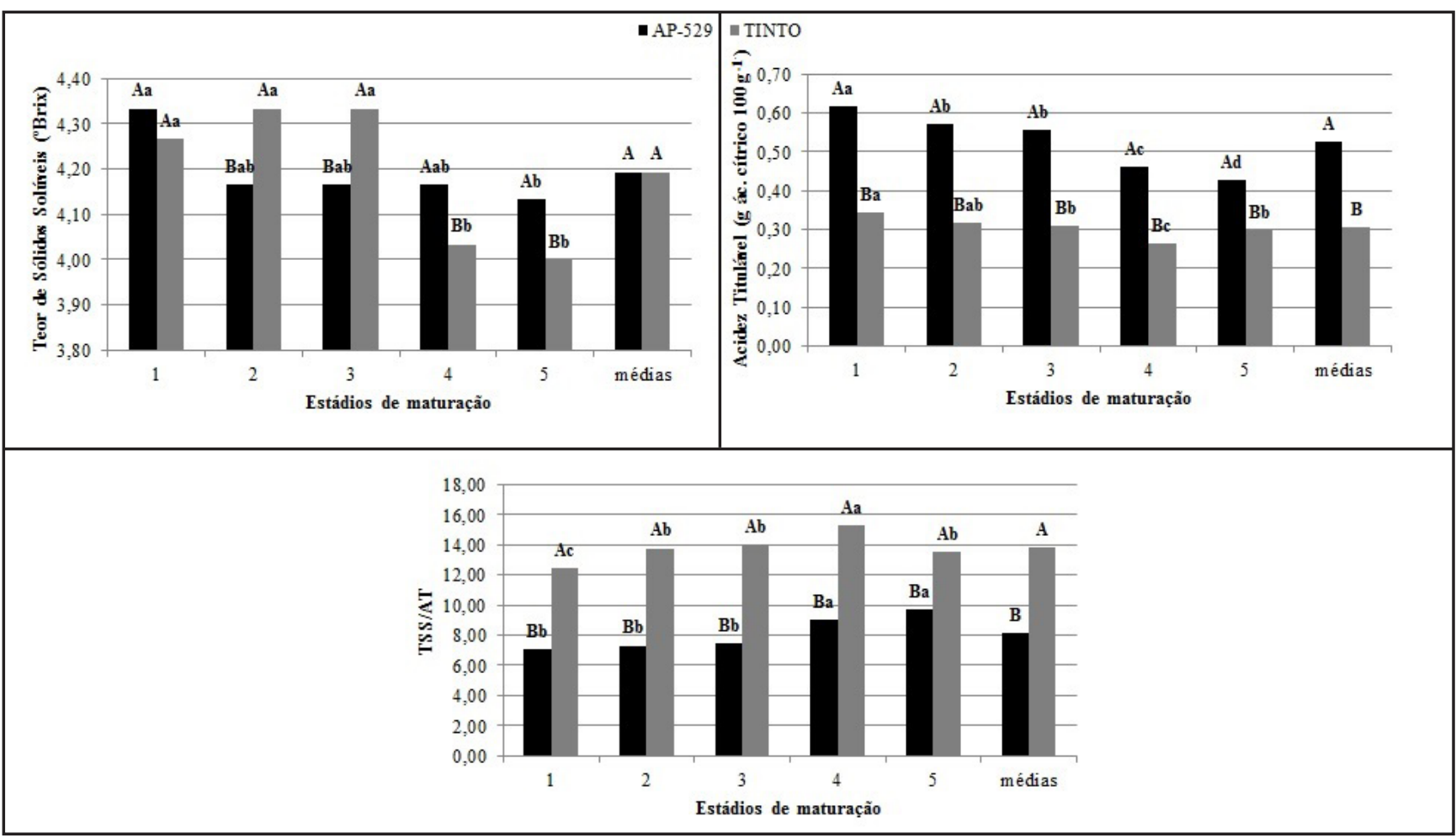

Figura 2. Teor de sólidos solúveis ( ${ }^{\circ}$ Brix), acidez titulável (g ácido cítrico/100 g de polpa) e relação TSS/ATT em híbridos de tomateiro colhidos em cinco estádios de maturação e avaliados no sexto estádio de maturação \{soluble solids content ( ${ }^{\circ}$ Brix), acidity ( $\mathrm{g}$ citric acid/100 g pulp) and TSS/TTA ratio in tomato hybrids harvested at five maturity stages and evaluated in the sixth stage of maturation\}. Letras maiúsculas comparam híbridos e letras minúsculas comparam estádios de maturação. Médias seguidas pela mesma letra (maiúscula ou minúscula) não diferem estatisticamente entre si pelo teste de Tukey a 5\% (uppercase and lowercase letters compare hybrids maturation stages, respectively. Means followed by same uppercase or lowercase letters did not differ significantly by the Tukey test at 5\%). Guarapuava, UNICENTRO, 2014.

valores nos estádios 1,2 e $3(4,27 ; 4,33$ e $4,33^{\circ}$ Brix, respectivamente) e os menores teores foram encontrados nos estádios 4 e $5\left(4,03\right.$ e $4,00^{\circ}$ Brix $)$.

O teor de sólidos solúveis é uma das características responsáveis pelo agradável sabor dos frutos, e pode ser influenciado por diversos fatores do ambiente, por fatores de manejo da cultura, como o estádio de maturação na colheita, assim também como por fatores intrínsecos do próprio fruto, principalmente a sua capacidade de dreno, ou seja, em importar fotoassimilados (Silva \& Giordano, 2000).

Segundo a Embrapa (2007), frutos colhidos em estádios menos avançados de maturação ficam mais tempo expostos à perda de água, ou seja, transpiram mais. A transpiração ocorre devido ao déficit de pressão de vapor (DPV), que é a diferença entre a pressão de vapor dos espaços intercelulares do produto e o ar circundante. O DPV depende da umidade relativa do ar e da temperatura, sendo que a perda de massa é maior em altas temperaturas e baixa umidade relativa (Woods, 1990). Esta é a principal causa da concentração de açúcares em virtude da concentração do suco celular.

Brackmann et al. (2007) concluíram em seu trabalho que o estádio de maturação não influenciou o teor de sólidos solúveis de tomate 'Cronus'. Estes autores explicaram que tomates colhidos parcialmente ou totalmente maduros apresentam, após o período de armazenamento, uma qualidade semelhante em termos de sabor cítrico/ 100 g) e que 'Cronus' foi estatisticamente superior ao híbrido Tinto $(0,31 \mathrm{~g}$ ácido cítrico/100 g). Essa característica também foi influenciada pelos estádios de maturação na colheita, sendo que o estádio 1 apresentou a maior acidez para o híbrido AP-529 (0,62 g ácido cítrico/100 g) assim como para o híbrido Tinto $(0,34$ $\mathrm{g}$ ácido cítrico/100 g), sendo superiores aos demais estádios. Os menores valores de acidez foram encontrados nos frutos colhidos em estádios mais avançados de maturação (estádios 4 e 5). Ferreira
(2004) afirma que frutos amadurecidos na planta mãe apresentam acidez mais baixa do que os amadurecidos fora dela. Segundo Zambrano et al. (1996), tomates cv. Rio Grande e Walter colhidos no estádio rosado (estádio 2) apresentaram 0,45 e $0,46 \mathrm{~g}$ ácido cítrico/ $100 \mathrm{~g}$, respectivamente e as mesmas cultivares colhidas no estádio vermelho apresentaram menores valores, 0,42 e $0,40 \mathrm{~g}$ ácido cítrico/100 g, respectivamente. Frutos da cv. Micra RS no estádio vermelho de maturação registraram $0,35 \mathrm{~g}$ ácido cítrico/100 g de acidez titulável (Lisiewska \& Kmiecik, 2000) e tomate cv. Durinta colhidos no estádio pintado (estádio 3) apresentam 0,40 g ácido cítrico/100 g de acidez titulável (Artés et al., 1999).

Essa variação encontrada na acidez titulável entre os híbridos é devido a muitos fatores, entre eles, o fator genético é determinante (Seleguini et al., 2007). A acidez titulável também está relacionada ao maior ou menor aproveitamento pela indústria, pois tomates que apresentam valores abaixo de $0,35 \mathrm{~g}$ 


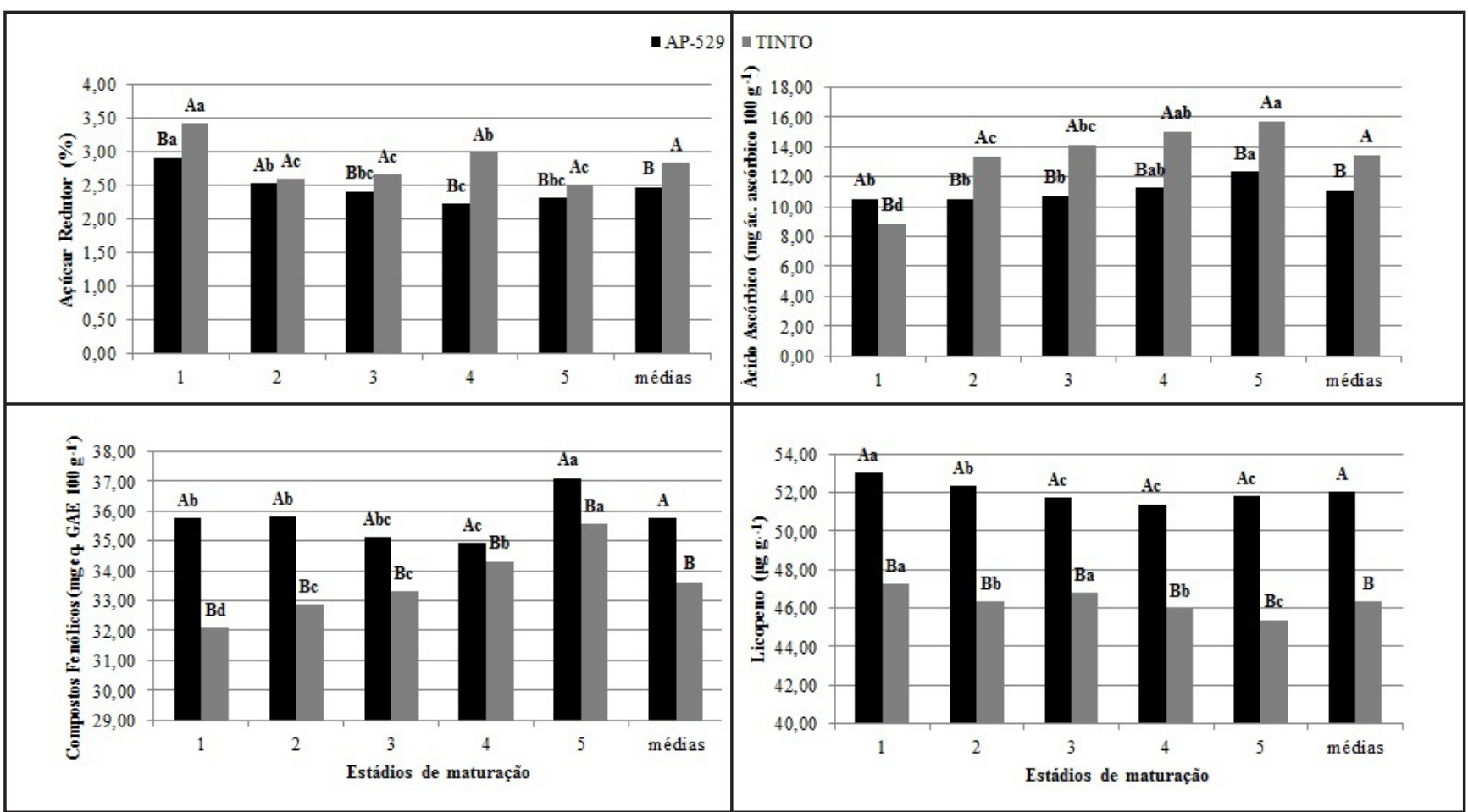

Figura 3. Açúcares redutores (\%), ácido ascórbico $(\mathrm{mg} / 100 \mathrm{~g})$, licopeno $(\mu \mathrm{g} / \mathrm{g})$ e compostos fenólicos (mg eq. GAE/100 g) em híbridos de tomateiro colhidos em cinco estádios de maturação e avaliados no sexto estádio de maturação \{reducing sugars (\%), ascorbic acid (mg/100 $\mathrm{g})$, lycopene $(\mu \mathrm{g} / \mathrm{g})$ and phenolic compounds (eq. GAE $100 \mathrm{mg} / \mathrm{g})$ in tomato hybrids harvested at different maturation stages and evaluated in the sixth maturation stage\}. Letras maiúsculas comparam híbridos e letras minúsculas comparam estádios de maturação. Médias seguidas pela mesma (maiúscula ou minúscula) não diferem estatisticamente entre si pelo teste de Tukey a 5\% (uppercase and lowercase letters compare hybrids and maturation stages, respectively. Means followed by the same uppercase or lowercase letters did not differ significantly by the Tukey test at 5\%). Guarapuava, UNICENTRO, 2014.

ácido cítrico/100 g de fruto fresco requerem aumento no tempo e temperatura de processamento para evitar a proliferação de microrganismos nos produtos processados (Silva \& Giordano, 2000).

A relação TSS/AT foi maior no híbrido Tinto $(13,80)$, sendo considerada uma boa relação, por estar acima de 10 (Figura 2). No híbrido AP-529 essa relação foi em média de 8,10 . Devido os estádios de maturação apresentarem influencia no TSS e na AT, o mesmo acontece com a relação entre eles. No híbrido AP-529 a maior relação foi encontrada nos estádios 4 e 5 (9,02 e 9,71, respectivamente) sendo superiores aos demais. Para o híbrido Tinto, essa maior relação foi encontrada no estádio $4(15,30)$, diferenciando significativamente das demais. Para Kader et al. (1978), frutos de alta qualidade contêm mais de 0,32 $\mathrm{g}$ ácido cítrico/100 g de acidez titulável, $3 \%$ de TSS e relação TSS/AT maior que 10. Alto valor na relação TSS/AT indica uma excelente combinação de açúcar e ácido que se correlacionam com sabor suave enquanto que os valores baixos se correlacionam com ácido e pior sabor dos frutos (Chitarra \& Chitarra, 2005).

Com relação aos açúcares redutores, o híbrido Tinto se destacou com o maior teor $(2,83 \%)$ sendo superior ao híbrido AP-529 (2,44\%) (Figura 3). Entre os estádios de maturação, em ambos híbridos, os frutos do estádio 1 apresentaram os maiores teores de AR que os demais estádios. O valor encontrado no estádio 1 para o híbrido AP-529 foi 2,90\% e para o Tinto de 3,42\%. Como já afirmado anteriormente para TSS, este fato pode ser explicado pela redução da permanência do fruto na planta, em que frutos desligados da planta mãe perdem mais água e concentram mais açúcar com o amadurecimento.

Zambrano et al. (1996), ao colher frutos de tomateiro no estádio verde (estádio 1) e maturados fora da planta encontraram valores variando de 3,07 a 2,63\%, ficando próximos dos valores encontrados nesse estádio por esse trabalho. Segundo Carvalho et al. (1984), frutos de tomate colhidos no estádio verde-rosa (estádio 2) apresentaram teores de AR significativamente superiores aos dos demais estádios.

Com relação ao teor de ácido ascórbico, o híbrido Tinto destaca-se com o maior valor observado $(13,40 \mathrm{mg} / 100$ g), enquanto que no híbrido AP-529 o teor encontrado foi de $11,06 \mathrm{mg} / 100 \mathrm{~g}$ (Figura 3). O estádio de maturação dos frutos no momento da colheita interfere no teor de ácido ascórbico. O estádio 5, tanto para o híbrido AP-529 como para o Tinto, apresenta o maior valor dessa vitamina, sendo superiores aos demais estádios. Para o AP-529, esse valor foi de $12,32 \mathrm{mg} / 100 \mathrm{~g}$ e para o Tinto o teor no estádio 5 foi de $15,71 \mathrm{mg} / 100$ g. Os menores valores encontrados estão nos estádios menos avançados de maturação.

$\mathrm{O}$ valor de vitamina $\mathrm{C}$ pode variar dependendo da genética da cultivar e é fortemente influenciado pelas condições do ambiente de cultivo, como por exemplo a intensidade luminosa durante 
o período de crescimento da planta e dos frutos, essa influenciando na biossíntese do ácido ascórbico (Lee et al., 2000). Os resultados encontrados estão de acordo com Zambrano et al. (1996) que, ao trabalhar com estádios de maturação, observaram que frutos colhidos maduros apresentam maior teor de vitamina $\mathrm{C}$ do que aqueles amadurecidos em ambientes fora da planta mãe, encontrando valor de $12,45 \mathrm{mg} / 100 \mathrm{~g}$ para frutos colhidos no estádio 5. Teores superiores a esse foram quantificados por Lisiewska \& Kmiecik (2000), no estádio vermelho (estádio 5), em torno de 23,60 mg/100 g.

Quanto aos compostos fenólicos, o híbrido com frutos de maior teor foi o AP-529 (35,01 mg/100 g) apresentando-se superior ao híbrido Tinto $(33,63$ mg/100 g) (Figura 3). Compostos fenólicos também são influenciados pelos fatores genéticos, associados ao processo de amadurecimento e ao metabolismo de compostos fenólicos da planta (Scalzo et al., 2005; Atkinson et al., 2006).

Observa-se com relação aos estádios de maturação, que frutos colhidos no estádio mais avançados de maturação (estádio 5) têm maior teor de compostos fenólicos do que aqueles colhidos menos maduros. No estádio 5, o híbrido AP-529 e Tinto, apresentaram respectivamente 37,10 e $35,56 \mathrm{mg} / 100 \mathrm{~g}$. Esse resultado pode ser explicado principalmente em função da radiação solar e da temperatura, em que os frutos mantidos na planta mãe estiveram expostos. Compostos fenólicos são metabólitos secundários e são produzidos pela planta em condições de estresses, podendo ser esse causado por pragas ou fatores climáticos. A radiação, principalmente a ultravioleta, está relacionada à produção de compostos fenólicos (Reay \& Lancaster, 2001; Andersen \& Jordheim, 2006).

O híbrido AP-529 destaca-se com maiores teores de licopeno com relação ao híbrido Tinto, 52,05 e 46,33 $\mu \mathrm{g} / \mathrm{g}$, respectivamente. Em frutos colhidos em estádios menos avançado de maturação encontram-se maiores conteúdos de licopeno, sendo superiores aos demais estádios. No híbrido AP-529, o teor de licopeno no estádio 1 foi de $53,01 \mu \mathrm{g} / \mathrm{g}$ e no híbrido Tinto o teor foi de 47,23 $\mu \mathrm{g} / \mathrm{g}$. A concentração do licopeno no tomate está relacionada com uma melhor percepção visual dos produtos, existindo, portanto, uma forte demanda para aumentar os teores deste pigmento em frutos das cultivares tanto para consumo in natura quanto para processamento industrial (Boileau et al., 2003).

O teor de licopeno é variável nos frutos conforme o grau de maturação, a cultivar de tomate e efeitos das condições de cultivo (Thompson et al., 2000). O fato pelo qual os frutos amadurecidos fora da planta apresentam o maior conteúdo de licopeno, pode ser explicado pela temperatura de exposição. A temperatura é um importante fator ambiental no desenvolvimento da cor do tomate. Temperaturas acima de $30^{\circ} \mathrm{C}$ são inibidoras para a síntese de licopeno, embora não afetem a síntese de betacaroteno (Eskin, 1989). Frutos amadurecidos na planta ficaram mais tempo expostos à temperatura elevada e maior intensidade de luz.

As características de qualidade dos frutos de tomate estão diretamente relacionas com o seu genótipo e ao estágio de maturação no momento da colheita. A procura de híbridos que se destaquem em vários atributos de qualidade é evidente, tanto para melhoristas, produtores e consumidores. O híbrido AP-529 teve destaque nos teores de compostos fenólicos e licopeno em relação ao hibrido Tinto. Também apresentou maior acidez titulável, porém o que levou à baixa relação TSS/AT, que não é desejável. O híbrido Tinto se destacou no teor de açúcares redutores, ácido ascórbico e, devido à menor acidez titulável, se destacou também com maior relação TSS/AT.

O estádio de maturação do fruto no momento da colheita interfere nas características de qualidade físico-química e nos compostos bioativos. A colheita dos frutos em estádios menos avançados de maturação favoreceu as características firmeza, sólidos solúveis, acidez titulável, açúcar redutor e licopeno, enquanto que a colheita em estádios mais avançados de maturação favoreceu a relação TSS/AT, compostos fenólicos e vitamina C proporcionando dessa forma melhores resultados do ponto de vista nutricional.

\section{REFERÊNCIAS}

ALVARENGA MAR. 2004. Tomate: produção em campo, casa-de-vegetação e em hidroponia. Lavras: UFLA. 400p.

ANDERSEN, OM; JORDHEIM M. 2006. The anthocyanins. In: ANDERSEN OM; MARKHAM KR (eds). Flavonoids: Chemistry, Biochemistry and applications. $551 \mathrm{p}$.

ARTÉS F; CONESA MA; HERNÁNDEZ S; GIL MI. 1999. Keeping quality of fresh-cut tomato. Postharvest Biology and Technology 17: 153-162.

ATKINSON CJ; DODDS PAA; FORD YY; LE MIÈRE J; TAYLOR JM; BLAKE PS; PAUL N. 2006. Effects of cultivar, fruit number and reflected photosynthetically active radiation on Fragaria $\mathrm{x}$ ananassa productivity and fruit ellagic acid and ascorbic acid concentrations. Annals of Botany 97: 429-441.

BENASSI MT; ANTUNES AJ. 1988. A comparison of methaphosphoric and oxalic acids as extractant solutions for the determination of vitamin $\mathrm{C}$ in selected vegetables. Brazilian Archives of Biology and Technology 31: 507-513.

BINOY G; KAUR C; KHURDIYADS; KAPOOR C. 2004. Antioxidants in tomato (Lycopersicon esculentum) as a function of genotype. Food Chemistry 84: 45-51.

BRACKMANNA; STEFFENS CA; ANDRIOLO JL; PINTO JAV. 2007. Armazenamento de tomates cultivar "Cronus" em função do estádio de maturação e da temperatura. Ciência Rural 37: 1295-1300.

BOILEAU TW; LIAO ZM; KIM S; LEMESHOW S; ERDMAN JW; CLINTON SK. 2003. Prostate carcinogenesis in N-methyl-Nnitrosourea (NMU) testosterone-treated rats fed with tomato powder, lycopene, or energyrestricted diets. Journal of the National Cancer Institute 95: 1578-1586.

CARVALHO VD; SOUZA SMC; CHITARRA MIF; CARDOSO DAM; CHITARRA AB. 1984. Qualidade de tomates da cultivar gigante Kada amadurecidos na planta e fora da planta. Pesquisa Agropecuária Brasileira 19: 489-493.

CHITARRA MIF; CHITARRA AB. 2005. Póscolheita de frutos e hortaliças: fisiologia e manuseio. Lavras: UFLA, 783p.

EMBRAPA. Sistema de Produção do Mirtilo. 2007, 2 de dezembro. Disponível em: $<$ http://sistemasdeproducao.cnptia. embrapa.br/FontesHTML/Mirtilo/ SistemaProducaoMirtilo/conservacao.htm>.

ESKIN, NAM. 1989. Quality and preservation of vegetables. Florida: CRC Press.

FERREIRA SMR; FREITAS RJS; LAZZARI EN. 2004. Padrão de identidade e qualidade do tomate (Lycopersicon esculentum) de mesa. Ciência Rural 34: 329-335.

FERREIRA RMA; LOPES WAR; AROUCHA EMM; MANO NCS; SOUSA CMGS. 2012. 
Caracterização física e química de híbridos de tomate em diferentes estádios de maturação produzidos em Baraúna, Rio Grande do Norte. Revista Ceres 59: 506-511.

GARCIA E; BARRETT DM. 2006. Assessing lycopene content in California processing tomatoes. Journal of Food Processing and Preservation 30: 56-70.

INSTITUTO ADOLFO LUTZ. Brasil. Ministério da Saúde. Agência Nacional de Vigilância Sanitária. 2005. Métodos fisico-químicos para análise de alimentos. Brasília: Ministério da Saúde.

KADER AA; MORRIS LL; STEVENS MA; ALBRIGHT-HOLTON M. 1978. Composition and flavor quality of fresh market tomato as influenced by some postharvest handling procedures. Journal of the American Society for Horticultural Science 103: 6-13.

LEE J; KOO N; MIN DB. 2000. Reactive oxygen species, aging and antioxidative nutraceuticals. Comprehensive Reviews in Food Science and Food Safety 3: 21-33.

LISIEWSKA Z; KMIECIK W. 2000. Effect of storage period and temperature on the chemical composition and organoleptic quality of frozen tomato cubes. Food Chemistry 70: 167-173.

LONG M; MILLAR DJ; KIMURAY; DONOVAN G; REES J; FRASER PD. 2006. Metabolite profiling of carotenoid and phenolic pathways in mutant and transgenic lines of tomato: Identification of a high antioxidant fruit line.
Phytochemistry 67: 1750-1757.

LÓPEZ-JUEZ E. 2007. Plastid biogenesis, between light and shadows. Journal of Experimental Botany 58: 11-27.

MATTEDI AP; SOARES BO; ALMEIDA VS; GRIGOLLI JFJ; SILVA LJ; SILVA DJH. In: SILVA DJH; VALE FXR. 2007. Tomate: tecnologia de produção. Viçosa: UFV. p.78-89.

RAFFO A; LEONARDI C; FOGLIANO V; AMBROSINO P; SALUCCI M; GENNARO L; BUGIANESI RO; GIUFRIDA F; QUAGLIA G. 2002. Nutritional value of cherry tomatoes (Lycopersicon esculentum Cv. Naomi F1) harvested at different ripening stages. Journal of Agricultural and Food Chemistry 50: 6550-6556.

REAY PF; LANCASTER JE. 2001. Accumulation of anthocyanins and quercetina glycosides in 'Gala' and 'Royal Gala' apple fruit skin with UV-B-Visible irradiation: modifying effects of fruit maturity, fruit side, and temperature. Scientia Horticulturae 90: 57-68.

RODRIGUEZ-AMAYA DA. 2001. Guide to carotenoids analysis in food. Washington: International Life Sciences Institute. 64p.

SCALZO J; POLITI A; PELLEGRINI N; MEZZETTI B; BATTINO M. 2005. Plant genotype affects total antioxidant capacity and phenolic contents in fruit. Nutrition 21: 207-213.

SELEGUINI A; SENO S; FARIA JÚNIOR MJA. 2007. Híbridos de tomateiro industrial cultivados em ambiente protegido e campo aberto. Científica 35: 80-87.

SILVA JBC; GIORDANO LB. 2000. Tomate para processamento industrial. Brasilia: Embrapa Comunicação para Transferência de Tecnologia/Embrapa Hortaliças 1: 8-11.

SINGLETON VL; ROSSI JA. 1965. Colorimetry of total phenolics with phosphomolybdicphosphotungstic acid reagents. American Journal of Enology and Viticulture 16: 144158.

SITRIT Y; BENNETT AB. 1998. Regulation of tomato fruit polygalacturonase mRNA accumulation by ethylene: A re-examination. Plant Physiology 116: 1145-1150.

THOMPSON KA; MARSHALL MR; SIMS CA; SARGENT SA; SCOTT JW. 2000. Cultivar, maturity, and heat treatment on lycopene content in tomatoes. Journal of Food Science 6: 791-795.

VRIES HSM; HARREN FJM; VOESENEK LACJ. 1995. Investigation of local ethylene emission from intact cherry tomatoes by means of photothermal and photoacoustic detection. Plant Physiology 107: 1371-1377.

WOODS JL. 1990. Moisture loss from fruits and vegetables. Postharvest News and Information 1: 195-199.

ZAMBRANO J; MOYEJA J; PACHECO L. 1996. Efecto del estado de madurez en la composición y calidad de frutos de tomate. Agronomia Tropical 46: 61-72. 